\title{
SOBRE UM TIPO INTERESSANTE DE MIIASE DOS BEZERROS E SEU AGENTE CAUSAL
}

\author{
POR \\ Z. Vaz e G. Teixeira de Carvalho \\ Com 4 figuras no texto
}

\section{INTRODUÇÃO}

Constitue o problema das mirases das mais importantes questões de patologia animal sobretudo nos países tropicais onde as condições climáticas são particularmente favoraveis á proliferação das moscas responsáveis; importante não só do ponto de vista econômico, em virtude dos grandes prejuizos que acarretam, principalmente nos bovinos, como tambem do ponto de vista parasitológico dada a variedade de tipos de miíases e de animais em que ocorrem, variedade ainda de agentes causais e de suas localisações e diversidade de ciclos biológicos dêstes.

E' pois de extranhar a diminuta atenção que entre nós se tem prestado ao problema que só foi ventilado em um ou outro de seus aspectos e, salvo pequenas notas relativas ás demais miíases, apenas aquelas determinadas por Oestridae mereceram investigação cuidada dos pesquizadores brasileiros.

São observações fundamentais as de A. NeIVA \& Florencio Gomes e de A. Lutz sobre a mosca do berne (Dermatobia hominis). demonstrando o complicado ciclo evolutivo dessa mosca; ainda ha pouco tempo R. v. Ihering e C. Neiva cuidaram da oestridiose em animais domésticos e v. Ihering assinalava no Estado de S. Paulo os primeiros casos autóctones de Gastrophilose dos equídeos que hoje são achado frequente de autopsia, mostrando a disseminação rápida, em nosso Estado, de uma parasitose importada com os cavalos do sul.

Vale recordar aqui que o termo «míase» não é o equivalente a «bicheira» utilizado pelo vulgo; enquanto que em patologia usa-se a palavra miíase para designar qualquer afecção determinada por larvas de dipteros Muscoidea, seja cutânea, subcutânea (berne), de cavidades naturais (Oestrus ovis) ou de orgãos internos (Gastrophilus veterinus), o povo apelida de "bicheira» apenas as miíases cutâneas, i. é., aquelas que se formam por deposição de numerosas larvas de moscas em pontos lesados da péle; as larvas destróem tecido são, de 
que se alimentam, fazendo assim grandes ulcerações repletas de larvas que aos poucos vão aumentando a úlcera em extensão e profundidade.

Em 1935 Z. VAZ poude reconhecer o agente causal de míases cutâneas no Brasil em tres espécies de animais domésticos (cão, porco e boi) obtendo os adultos por cultura das larvas retiradas de bicheiras desses animais. Nessa ocasião foi demonstrado pela primeira vez que, no Brasil, a mosca responsavel pelas miíases cutâneas de animais domésticos é a Cochliomyia hominivorax (CocQ. 1858) e não a C. macellaria como foi e é largamente escrito e repetido. Confirmava-se assim em condições naturais e para varios animais domésticos, a verificação de Cushing \& PAtton nos Estados Unidos em miíases de boi. A C. macellaria não destróe tecido são; nutre-se de materiais orgánicos em decomposição e se aparece nas bicheiras só o faz secundariamente quando as larvas de $C$. hominivorax destruindo tecido são, provocam o aparecimento de matéria morta, i. é. do pûs sanguinolento que escorre das bicheiras. Desempenha pois a $C$. macellaria em relação ás milases cutâneas (não nos referimos ás cavitárias), o mesmo papel que as Sarcofagas, Syntesiomiías, Lucilias, etc., i. é, agentes de invasão secundária.

Claro que tudo isso diz respeito ao continente americano pois é sabido que em outros, são diferentes as moscas verdadeiramente parasitas.

Em 1936 Townsend de S. Paulo publicou observações sobre a C. hominivorax e sabemos por informação dos Drs. H. DE SouzA Lopes e Jayme Lins de Almeida que, no Rio de Janeiro, tambem identificaram a $C$. hominivorax em miíases cutâneas.

\section{DESCRIÇÃO :}

De ha muito nos pedira o prof. Lauro TrAvassos que procurássemos verificar um fáto por ele notado ha bastante anos em Angra dos Reis; era uma interessante fórma de míases em bezerros no período de lactação, consistindo na presença de algumas larvas de moscas na cavidade gengivo-alvéolar dos dentes na fase de erupção. Procurámos em S. Paulo a ver se encontravamos fáto idêntico e um de nós (G. T. Carvalho), que aliás já conhecia essa miíase de sua experiencia clínica, encontrou alguns casos em uma granja dos arredores de S. Paulo e mais tarde em outras zonas do Estado.

Nos casos verificados por nós, a bicheira localisa-se num ponto da gengiva correspondente á solução de continuidade que se fórma por ocasião da erupção de cada um dos incisivos. $\mathrm{Na}$ cavidade alveolar atacada encontra-se sempre pequeno número de larvas, uma a duas, no máximo quatro a seis o que se explica pelo espaço restrito de que dispõem as larvas, espaço que se torna mais acanhado á medida que o dente vae emergindo do alvéolo. 
Esta fórma de miŕase, apenas localisada no alvéolo, e que não deve ser confundida com a miíase bucal que interessa a quasi totalidade da boca com grande destruição de tecidos, é bem conhecida de alguns tratadores de bezerros como pudemos verificar. Devemos notar que os bezerros atacados que examinamos, tinham todos no máximo um mês de vida ou seja até a idade em que, nos animais de crescimento normal, rompem todos os incisivos e não observamos larvas em bezerros com dentes já formados. Informou-nos todavia, o Prof. Milton Piza que não é incomum encontrar em bezerros mais velhos lar-

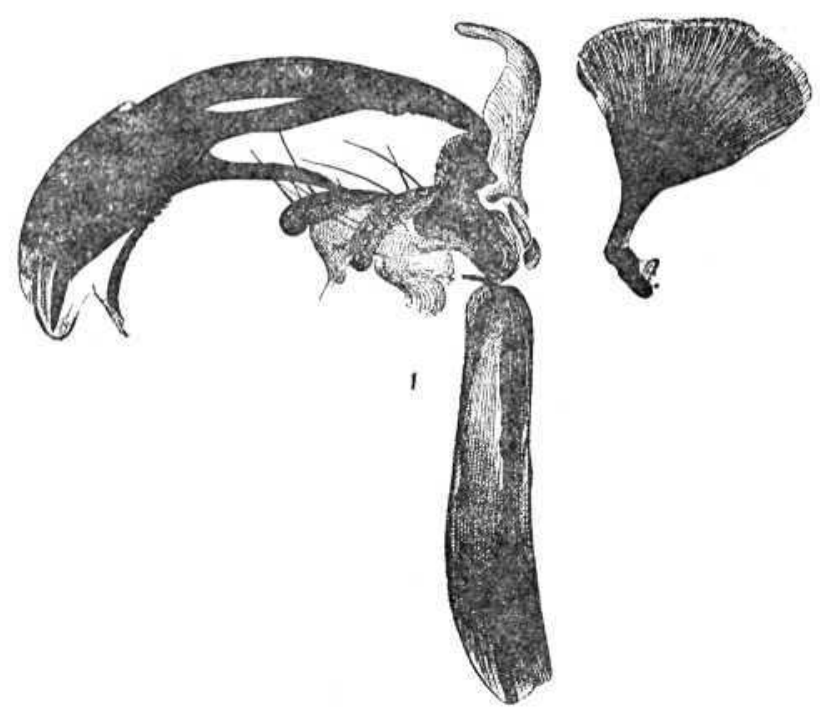

Fig. 1 - Falosoma e parameros de C. hominivorax

vas localisadas entre o alvéolo e o dente respectivo, fáto que se explica porque a raiz não ocupa toda a cavidade alvéolar. Foi só no período de verão que encontrámos tal fórma de míase e essa é aliás a época mais propícia ao desenvolvimento das moscas.

\section{SINTOMAS:}

Nem por ser diminuto o número de larvas no alvéolo atacado, são menos caracteristicos os sintomas clínicos da moléstia. O estado geral dos bezerros era sempre satisfactório nos casos observados, notando-se porém um certo gráo de impaciência e um contínuo movimento de protração e retração da língua (para fóra e para dentro da boca,) dando-se a saída sempre pelo mesmo lado, correspondente aliás áquele em que se localisou a miíase. O movimento de vae e vem da língua chama logo a atenção do observador o qual com facilidade póde veri- 
ficar a presença das larvas. Em virtude do raspar da língua sobre a gengiva, consequencia talvez do prúrido contínuo produzido pelas larvas, ocorre sempre forte congestão local e em alguns casos saída de sangue, avermelhando a saliva que escorre pelos cantos da boca.

\section{ETIOLOGIA :}

Cuidamos de cultivar em laboratório as larvas retiradas do alvéolo atacado com o fito de obter os adultos os quais permitem identificação específica mais rigorosa. As larvas retiradas eram colocadas em um vidro com terra e deixadas á temperatura ambiente e é claro que só puparam aquelas que haviam atingido o completo crescimento larvar. Apenas quatro exemplares, tres machos e uma fêmea,

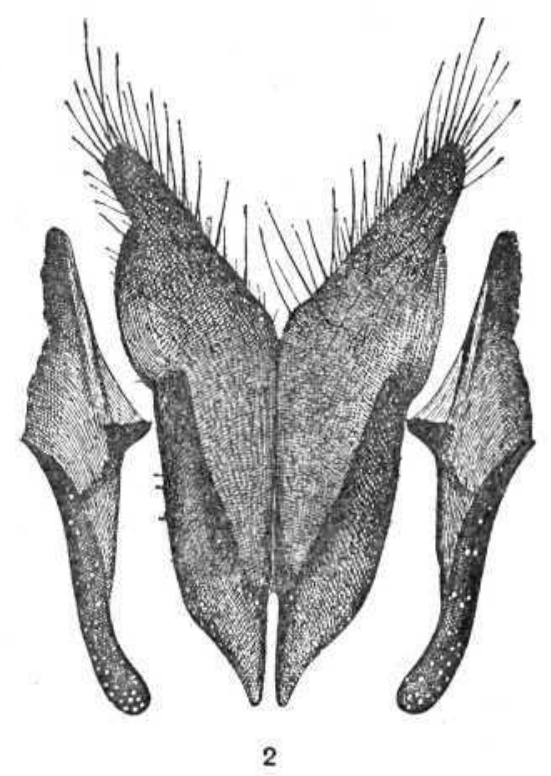

Fig. 2 - IX.o cocito de C. hominivorax

foram assim obtidas; as demais larvas não prosseguiram a evolução mas aqueles adultos foram suficientes para proceder a identificação. O exame do hipopígio conforme propuzeram Cushing \& PATTON (1933) e o aspecto da frontália, segundo foi indicado por $\mathrm{V}_{\mathrm{AZ}}$ (1935) mostraram que se tratava da Cochliomyia hominivorax CocQ., 1858, a mesma mosca responsavel pelas miíases cutâneas.

Quanto a maneira pela qual as larvas se instalam no alvéolo só podemos fazer hipóteses pois nada pudemos observar. E' de se admitir porém que as fêmeas de Cochliomyia hominivorax, repletas de ovos, sejam atraídas pelo depósito adocicado existente nos cantos da boca e que se fórma por evaporação da água do leite que sempre 
escapa por aí enquanto os bezerros mamam. Depostos os ovos nos bordos da boca, as larvas eclodem e caminhariam então para dentro da boca instalando-se na solução de continuidade da gengiva que se fórma onde os dentes vão emergir.

\section{TRATAMENTO:}

Os tratadores de bezerros cuidam dos animais atacados comprimindo a gengiva ao nivel do alvéolo lesado, provocando assim a emergência das larvas que são retiradas mecanicamente. Esse é aliás o tratamento indicado, pois a utilização de desinfectantes á base de

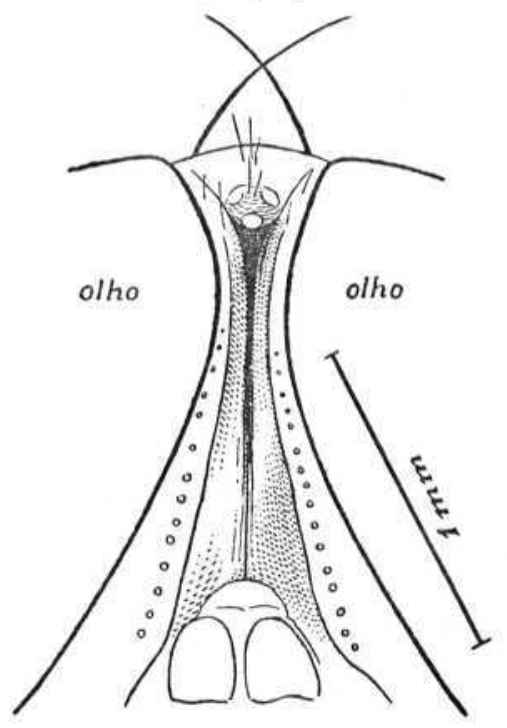

3

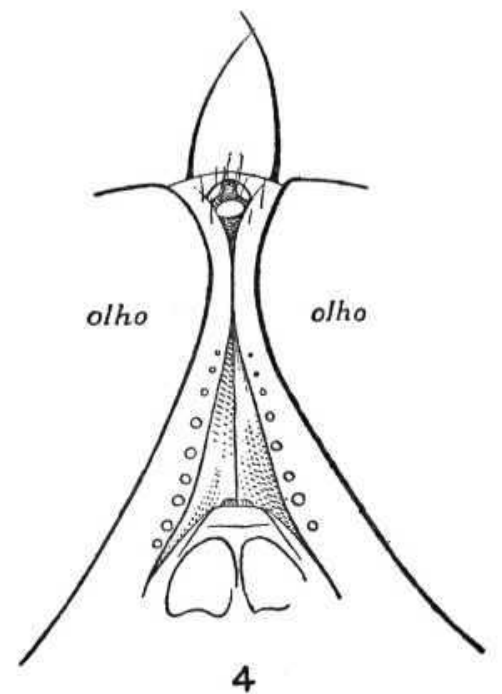

4

Fig. 3 - Frontalia do macho de C. hominivorax. Fig. 4 - Frontalia do macho de C. macellaria. Seg. Vaz (1935).

cresol (Creolinas) tão eficiente na terapêutica das miíases cutâneas, talvez produza na gengiva irritação de consequências quiçá piores que a miíase.

Após a retirada mecanica das larvas, que se obtem com muita facilidade é indicado pincelar a região lesada com glicerina iodada, na proporção de uma parte de tintura de iodo para tres de glicerina.

\section{On curious type of myiases on young calves and its causal agent.}

The authors report a curious type of myiases on young calves in the State of São Paulo, Brasil, occurring during their first month of life, when the incisors are cutting. 
The larvae, numbering one, two or six at the most, install themselves in the effraction of the gums, where they develop and reach the alveolar cavity therefrom.

The infested animals continuosly stretch their tongues out of their mouths, through the side corresponding to the diseased alveolus. Sometimes the larvae remain after the incisor has cut, occupying the space between the root of the tooth and the wall of the alveolus.

The health of the calves does not markedly suffer. The treatment consists in forcing the larvae out of their location by pressing the calf's gums with the fingers.

Adults were bred from maggots and identified as Cochliomyia hominivorax (CocQ., 1858) (Syn. C. americana Cushing \& PATton, 1933), which is to be considered as the cause of the myiases. The identification was based upon the examination of the male's genitalia acording to CusHING \& PATTON (1933) and the aspect of the frontalia acording to VAZ (1935).

\section{BIBLIOGRAFIA}

Aubertin, D. \& Buxton, P. A. - 1934 - Cochliomyia and Myiasis in Tropical America. Ann. Trop. Med. Par., 28, 245.

Cushing, E. \& Patton, W. S. - 1933 - Studies on the Higher Diptera of Medical and Veterinary Importance. Cochliomyia americana sp. nov., the Screw Worm of the New World. Ann. Trop. Med. Par. 27, 593.

Townsend, Сн. - 1936 -- On Cochliomyia hominivorax Cocq. (Dipt). Rev. Entom. 6, (3-4) 485.

VAZ, Z. - 1935 - Cochliomyia hominivorax agente causal de miíases em animais domésticos do Brasil (Caracteres que permitem distingui-la de C. macellaria). Rev. Biol. Hyg. 6, (1) 13. 